\title{
NON-SPECIFIC FACTORS OF CHILDREN PROTECTION WITH STREPTOCOCCAL TONSILLITIS AND INFECTED WITH HERPES VIRUS TYPE 6
}

\author{
Viktoriia Olkhovska, Zalina Yeloeva, Yevhen Olkhovsky
}

The aim of the work was to study the characteristics of the response of non-specific protective factors in tonsillitis of streptococcal etiology in children infected and uninfected with HHV-6 infection at different periods of the disease.

Materials and research methods. In 78 children aged 3-15 years, inflammation markers and phagocytic activity of peripheral blood neutrophils (PAN) were determined using the nitroblue tetrazolium reduction test. The studies were carried out in the acute period and in the period of convalescence. Mathematical and statistical processing of the data obtained was carried out using Microsoft Excel 2003 and Statistica 6.0 programs. The significance of differences between the mean values was determined using the Student's test ( $t$ ).

Results. It was found that infection of children with HHV-6 leads to a decrease in the functional activity of neutrophils in the onset of streptococcal tonsillitis compared with uninfected patients $(p<0.05)$. Also, the acute period of streptococcal tonsillitis in patients with co-infection is accompanied by a violation of the functional reserve of the oxygendependent mechanism of bactericidal neutrophils: minimal opportunities were found in tonsillitis on the background of HHV-6 infection ( $p<0.05)$. By the period of convalescence, a decrease in the indicators of the functional activity of neutrophils, increased in the acute period, was recorded, but in children infected with HHV-6, a complete recovery of indicators to the physiological norm did not occur. One of the features of streptococcal tonsillitis in children with HHV-6 infection is an increase in serum gamma globulin level $(p<0.05)$, lack of significant dynamics of decrease in the ASL-O indicator.

Conclusions. The presence of VHL-6t infection in a child with streptococcal tonsillitis adversely affects the state of nonspecific protective factors, in particular PAN. The obtained data must be used to optimize the management of patients at different periods of the disease, including at the stages of dispensary observation

Keywords: non-specific protective factors, phagocytosis, streptococcal tonsillitis, herpes virus type 6

How to cite:

Olkhovska, V., Yeloeva, Z., Olkhovsky, Y. (2021). Non-specific factors of children protection with streptococcal tonsillitis and infected with herpes virus type 6. ScienceRise: Medical Science, 5 (44), 31-35. doi: http://doi.org/10.15587/2519-4798.2021.240151

(C) The Author(s) 2021

This is an open access article under the Creative Commons CC BY license hydrate

\section{Introduction}

Tonsillitis of streptococcal etiology in children remains one of the most common pathologies, which may be accompanied by severe complications in the acute period, as well as lead to adverse consequences in the future due to the risks of cardiovascular, connective tissue, kidney diseases, etc. $[1,2]$. Given the high percentage of infection of children at an early age with herpes viruses, which could adversely affect the outcome of any disease, it is important to determine the factors that shape the course of the disease [3]. Even the asymptomatic persistence of herpes viruses in the human body can lead to "failures" in the normal functioning of human defence systems $[4,5]$. There are many scientific studies of the effects of Epstein-Barr virus, cytomegalovirus on the child $[6,7]$, but studies of human herpes virus type 6 (HHV-6) and its importance in responding to specific and non-specific factors of child protection with streptococcal tonsillitis is not enough. However, the recovery of a child with tonsillitis depends of an adequate immune response and the timely response of non-specific protective factors.

In bacterial infections, the state of functional activity of neutrophils and monocytes is extremely important, which is examined by the nitrosine tetrazolium reduction test (NRT test) in both infectious and somatic diseases, and also used as one of the criteria for complete recovery in infectious pathology [8]. Creactive protein (CRP) and the results of proteinogram studies are widely used as markers of the severity of the inflammatory process, including the presence of latent inflammation [9].

Unfortunately, in the sources available to us, we did not find research on the status of non-specific protective factors in children with tonsillitis and infected with HHV-6t.

The aim of the work is to study the peculiarities of the response of nonspecific protective factors in tonsillitis of streptococcal etiology in children infected and uninfected with HHV-6t in different periods of the disease. 


\section{Materials and methods of the research}

On the basis of the municipal non-profit company of the Kharkiv Regional Council "Regional Children's Infectious Diseases Hospital" in Kharkiv during 20182021 was surveyed 78 children aged 3 to 15 years (9.2 \pm 1.3 years) were treated with a diagnosis of tonsillitis caused by hemolytic streptococcus group A (GSHA). Two observation groups were identified. The first group consisted of 36 children with tonsillitis, which occurred on the background of HHV-6t infection (co-infection the main group). The second group included 42 children with tonsillitis without co-infection with any virus (mono-infection - comparison group).

The work was carried out in accordance with the principles of the Declaration of Helsinki adopted by the General Assembly of the World Medical Association (1964-2000), the Council of Europe Convention on Human Rights and Biomedicine (1997), relevant WHO provisions, the International Council of Medical Societies, the International Medical Code ethics (1983) and laws of Ukraine.

Informed consent was obtained from the parents of all patients who participated in the study. The Committee of the Bioethics Commission approved and confirmed the protocol No. 3 dated 18.10.2018.

Children in the observation groups were comparable in age $(8.92 \pm 1.44$ and $10.87 \pm 1.15$ years, $p>0.05)$ and sex. In all children, moderate tonsillitis was registered, the etiology of which was confirmed by the isolation of S. pyogenes in the bacteriological examination of smears from the nasopharynx and oropharynx.

Persistent HHV-6t infection was recorded when high titers of IgG antibodies to HHV-6t were detected. Simultaneous PCR blood and saliva testing for HHV-6t was negative in all patients. The results of studies (by
ELISA for antibodies IgG and IgM and PCR for viruses) of patients with other herpes viruses were negative.

Simultaneously with the laboratory and instrumental research methods, the determination of acute phase parameters and phagocytic activity of neutrophils (FAN) of peripheral blood was performed. FAN was assessed according to their ability to absorb the S. aureus bacteria (strain 209) Oxygendependent activity of phagocytes was studied in the spontaneous and zymosan stimulated nitrosine tetrazolium reduction test (NRTs and NRTsp test). The level of C-reactive protein was determined by the method of radial immunodiffusion, proteinogram parameters were determined by optical analysis (turbidimetry) and antistreptolysin-O parameters determined by the method of immunoturbidimetry.

The control group consisted of 20 healthy children, similar in age and sex. Static processing of the obtained results was performed using Excel and Statistica 6.0.

Mathematical and statistical processing of the data obtained was carried out using Microsoft Excel 2003 and Statistica 6.0 programs. The significance of differences between the mean values was determined using the Student's test ( $\mathrm{t}$ ). The assessment of the reliability of the correlation coefficient was carried out according to standard tables.

\section{Research results}

The phagocytic activity of neutrophils and proteinogram parameters of patients with tonsillitis of streptococcal etiology in the acute period of the disease (1-2 days of the disease) and in the period of early convalescence (8-10 days) were studied.

Table 1 shows the results of the studied indicators in the acute period.

Table 1

Phagocytic activity of neutrophils in patients and indicators of the proteinogram of patients in the acute period, (M $\pm \mathrm{m})$

\begin{tabular}{|l|c|c|c|}
\hline \multicolumn{1}{|c|}{ Indicators } & The first group $(\mathrm{n}=36)$ & $\begin{array}{c}\text { The second group } \\
(\mathrm{n}=42)\end{array}$ & $\begin{array}{c}\text { Control group } \\
(\mathrm{n}=20)\end{array}$ \\
\hline NRTsp, \% & $25.65 \pm 1.08^{1,2}$ & $31.04 \pm 0.64^{1}$ & $19.18 \pm 2.08$ \\
\hline IANsp, un. & $1.05 \pm 0.12$ & $1.48 \pm 0.13^{1}$ & $0.94 \pm 0.23$ \\
\hline NRTst, \% & $37.11 \pm 0.87^{2}$ & $44.02 \pm 1.84^{1}$ & $35.05 \pm 2.09$ \\
\hline IANst, un. & $1.67 \pm 0.12$ & $2.82 \pm 0.35^{1}$ & $1.25 \pm 0.36$ \\
\hline Total protein, g/l & $60.45 \pm 1.58$ & $63.46 \pm 2.47$ & $61.78 \pm 2.18$ \\
\hline Albumins, \% & $55.48 \pm 2.08$ & $58.55 \pm 1.97$ & $57.76 \pm 3.48$ \\
\hline Alpha globulins, \% & $13.45 \pm 2.01$ & $16.11 \pm 1.67$ & $15.28 \pm 1.84$ \\
\hline Beta globulins, \% & $9.11 \pm 1.13$ & $11.88 \pm 1.77$ & $10.75 \pm 1.09$ \\
\hline Gamma globulins, \% & $18.81 \pm 1.86^{1}$ & $15.55 \pm 1.48$ & $12.19 \pm 1.04$ \\
\hline
\end{tabular}

Note: ${ }^{l}$ - the probability of the sign to the control group; ${ }^{2}-$ the probability of the sign between the first and second groups

In the onset of streptococcal tonsillitis, there is a significant increase in the FAN of patients with the maximum increase in the NRT test in patients with monoinfection $(\mathrm{p}<0.01)$. It was determined that in the first group the rate of NRTsp test was probably lower than the results of patients in the second group $(\mathrm{p}<0.05)$. Comparison of IANsp patients in the control group showed that in co-infection this indicator did not increase significantly $(\mathrm{p}>0.05)$, while in the second group it was probably higher $(\mathrm{p}<0.05)$.
The functional reserve of the oxygen-dependent mechanism of bactericidal neutrophils revealed minimal opportunities in tonsillitis on the background of HHV $6 \mathrm{t}$ infection: the data of the NRTst test of these patients did not differ significantly from the control group ( $\mathrm{p}>0.05)$. In mono-infection, a significant increase in the NRT test was registered: the obtained data differed both in comparison with the control group $(\mathrm{p}<0.01)$ and in patients of the first group $(\mathrm{p}<0.001)$. Patients in the second group also had the highest IANst values $(\mathrm{p}<0.01)$. 
We did not find a significant difference in the main indicators of the proteinogram in patients with tonsillitis depending on the presence of infection with HHV6t infection, except for the content of gamma globulins. The concentration of the latter was significantly higher in patients with co-infection compared to the control group $(\mathrm{p}<0.05)$. Patients in both groups showed elevated levels of CRP $(36.48 \pm 2.15 \mathrm{mg} / \mathrm{l}$ and $39.42 \pm 2.91 \mathrm{mg} / \mathrm{l}$, respec- tively, in groups), which probably did not differ from each other, $\mathrm{p}>0.05$.

Determination of antistreptolysin-O (ASL-O) did not reveal a significant difference in both groups $(245.4 \pm 12.45 \mathrm{IU} / \mathrm{ml}$ and $258.11 \pm 13.52 \mathrm{IU} / \mathrm{ml}$, respectively, in the groups, $\mathrm{p}>0.05)$. Table 2 shows the results of the studied indicators in the period of convalescence of tonsillitis.

Table 2

Phagocytic activity of neutrophils in patients and proteinogram of patients in the period of convalescence, $(\mathrm{M} \pm \mathrm{m})$

\begin{tabular}{|l|c|c|c|}
\hline \multicolumn{1}{|c|}{ Indicators } & The first group $(\mathrm{n}=36)$ & $\begin{array}{c}\text { The second group } \\
(\mathrm{n}=42)\end{array}$ & $\begin{array}{c}\text { Control group } \\
(\mathrm{n}=20)\end{array}$ \\
\hline NRTsp, \% & $23.81 \pm 0.74^{1}$ & $22.06 \pm 1.08$ & $19.18 \pm 2.08$ \\
\hline IANsp, un. & $1.01 \pm 0.24$ & $1.26 \pm 0.25$ & $0.94 \pm 0.23$ \\
\hline NRTst, \% & $33.87 \pm 0.57^{2}$ & $36.14 \pm 0.76$ & $35.05 \pm 2.09$ \\
\hline IANst, un. & $1.54 \pm 0.21$ & $1.64 \pm 0.68$ & $1.25 \pm 0.36$ \\
\hline Total protein, g/l & $59.34 \pm 1.16$ & $60.09 \pm 1.97$ & $61.78 \pm 2.18$ \\
\hline Albumins, \% & $54.87 \pm 1.79$ & $56.11 \pm 1.38$ & $57.76 \pm 3.48$ \\
\hline Alpha globulins, \% & $15.55 \pm 1.83$ & $15.02 \pm 1.44$ & $15.28 \pm 1.84$ \\
\hline Beta globulins, \% & $12.53 \pm 1.22$ & $11.44 \pm 1.57$ & $10.75 \pm 1.09$ \\
\hline Gamma globulins, \% & $15.61 \pm 1.08^{1}$ & $13.97 \pm 1.16$ & $12.19 \pm 1.04$ \\
\hline
\end{tabular}

Note: ${ }^{1}$ - the probability of the sign to the control group ${ }^{2}$ - the probability of the sign between the first and second groups

In the period of convalescence of tonsillitis, a decrease in increased in the acute period PAN, which in patients with mono-infection approached the control group ( $p>0.05)$, and in patients of the first group remained significantly higher $(\mathrm{p}<0.05)$. IANsp in all patients before the convalescence period decreased and did not differ from the control group ( $\mathrm{p}>0.05)$.

Prior to the period of convalescence of tonsillitis, an improvement in the metabolic potential of neutrophils was observed in patients: NRTst data in the groups did not differ significantly from the control group ( $p>0.05)$. However, it is noteworthy that the reduced indicators of NRTst in patients of the first group, which differed significantly from those of patients of the second group $(\mathrm{p}<0.05)$.

By the convalescence period, the IANst index decreased significantly in patients of the second group $(p<0.05)$; and in all patients IANst did not differ significantly from the control group ( $\mathrm{p}>0.05)$.

\section{Discussion}

Thus, the acute period of streptococcal tonsillitis in children on the background of HHV-6t infection is accompanied by a probable increase in PAN (but less pronounced compared with patients with mono-infection) and a decrease in the functional reserve of oxygen-dependent bactericidal mechanism of neutrophils. The obtained results coincide with the data of Halych O. M. et al., 2019 [10], who investigated the reduction of phagocytosis in children, but these studies were performed in patients with minimal clinical manifestations of HHV-6t infection. Tonsillitis caused by GSHA in patients with mono-infection in the acute period is characterized by an increase in PAN with a high functional reserve of their bactericidal properties. During the period of convalescence in patients with co-infection there was no complete recovery of non-specific protection of the body: in comparison with the control group remained PAN stress on NRTsp $(p<0.05)$ with depletion of neutrophil metabolic activity by NRTst compared to the second group $(\mathrm{p}<0.05)$.
During the period of convalescence of tonsillitis in patients with HHV-6t infection, the increased content of gamma globulins remained, which differed significantly from the control group $(\mathrm{p}<0.05)$. Our results show that the combination of HHV-6t with tonsillitis caused by GSHA is accompanied by high numbers of serum gamma globulins, because the presence of HHV-6t in a child is not accompanied by significant fluctuations in this indicator and does not depend on process activity [10]. By the convalescence period, there was a significant decrease in CRP and ASL-O, which in patients of the second group approached the norm $(5.49 \pm 0.44 \mathrm{mg} / 1$ and $169.43 \pm 13.48 \mathrm{IU} / \mathrm{ml}$, respectively, $\mathrm{p}>0.05)$. In patients with co-infection, CRP probably did not differ from the norm $(5.11 \pm 0.37 \mathrm{mg} / 1, \mathrm{p}>0.05)$. The content of ASL-O in patients of the first group was increased $(219.79 \pm 12.95$ $\mathrm{IU} / \mathrm{ml}$ ), significantly different from the data of the second group, $\mathrm{p}<0.05$.

In our opinion, this fact indicates the adverse effects of HHV-6t infection on the course of streptococcal infection, may be one of the signals of incomplete rehabilitation of the body from bacteria and the risk of recurrence. Such patients require re-examination for ASL-O at least monthly until normalization. Careful outpatient follow-up and additional examinations of such patients are appropriate and given the adverse effects of streptococcal infection on herpes viruses. It is known that in persons infected with herpes viruses, the stratification of any acute infectious pathology, in particular - GSHA, can activate the replication of the virus [11] and lead to adverse effects.

Our data on the peculiarities of streptococcal tonsillitis in children on the background of the persistence of HHV$6 \mathrm{t}$ are important in terms of optimizing the management of patients in different periods of the disease, providing sound recommendations for outpatient follow-up.

Study limitations. The limitations for this study are acquired or congenital immunodeficiency states, longterm use of corticosteroids or immunosuppressants. 
Prospects for further research. Investigations of the peculiarities of the course of streptococcal tonsillitis against the background of HHV-6 in children will further contribute to the early diagnosis of the presence of a child's infection with the virus, as well as to predict the outcomes of streptococcal tonsillitis.

\section{Conclusions}

1. The presence of background infection with HHV-6t significantly affects the state of non-specific protective factors in children with streptococcal tonsillitis.

2. The course of streptococcal tonsillitis in children infected with HHV-6t is accompanied by a decrease in the functional reserve of the oxygendependent mechanism of bactericidal neutrophils in the acute period of the disease. The NRTst index in these patients did not exceed $38 \%$ compared to $44 \%$ in uninfected children.
3. By the period of convalescence of streptococcal tonsillitis in children infected with HHV-6t, the indicators of functional activity of neutrophils are not restored to physiological norm. Thus, the NRTsp index in these patients remained elevated and significantly differed from the norm $(23.81 \pm 0.74 \%, \mathrm{p}<0.05)$.

4. For children with tonsillitis, which occurs on the background of persistent HHV-6t infection, is characterized by elevated levels of gamma globulin in the acute period and in the convalescence stage, the preservation of elevated levels of ASL-O.

\section{Conflict of interests}

The authors declare that they have no conflicts of interest.

\section{Financing}

The study was performed without financial support.

\section{References}

1. Bobruk, S. V. (2018). Rational antibiotic therapy in treatment of bacterial tonsillitis in children. Reports of Vinnytsia National Medical University, 22 (2), 301-305. doi: http://doi.org/10.31393/reports-vnmedical-2018-22(2)-14

2. El Hennawi, D. E. D., Geneid, A., Zaher, S., Ahmed, M. R. (2017). Management of recurrent tonsillitis in children. American Journal of Otolaryngology, 38 (4), 371-374. doi: http://doi.org/10.1016/j.amjoto.2017.03.001

3. Kramarov, S. O., Yevtushenko, V. V. (2019). Modern approaches to the treatment of herpetic infection in children. Actual Infectology, 7 (3), 144-149. doi: http://doi.org/10.22141/2312-413x.7.3.2019.170993

4. Vinohradova, V. O., Honcharova, N. P., Yeremenko, A. B. (2017). Osoblyvosti klinichnoi kartyny infektsiinoho mononukleozu Ebshteina-Bar virusnoi etiolohii u ditei, infikovanykh virusom herpesu liudyny 6 typu. Medytsyna 21 storichchia. Kharkiv, 34-35.

5. Gilyuk, O. G., Bulat, L. M. (2017). Children age clinical peculiarities of herpes infections. Biomedical and biosocial anthropology, 28, 112-116.

6. Khodak, L. A., Brailko, V. I., Dejneka, N. G. (2018). Cytomegalovirus-induced hepatitis in children. Child`S Health, 13, 95-99. doi: http://doi.org/10.22141/2224-0551.13.0.2018.131188

7. Yang, Y., Gao, F. (2020). Clinical characteristics of primary and reactivated Epstein- Barr virus infection in children. Journal of Medical Virology, 92 (12), 3709-3716. doi: http://doi.org/10.1002/jmv.26202

8. Hans, M., Kalinichenko, S. V., Sklyar, N. I., Dubinina, N. V. (2018). Immunological indicators in patients with chronic tonsillitis following treatment by traditional methods and using high-energy laser. Bulletin of Problems Biology and Medicine, 1.1 (142), 209-212. doi: http://doi.org/10.29254/2077-4214-2018-1-1-142-209-212

9. Yeriomenko, R. F., Ostapets, M. O. (2017). Informativity of proteinograms as a clinical-diagnostic test at dispoteinemia in the age aspect. Journal of Education, Health and Sport, 7 (2), 479-488. doi: http://dx.doi.org/10.5281/zenodo.399312

10. Galich, E. N., Solovyeva, I. L., Kuselman, A. I., Solovyeva, A. A., Zakuraeva, K. A., Lankov, V. A. (2019). Phagocytosis and Antibody Mediated Immunity in Children Infected with Human Herpes Virus 6. Doctor.Ru, 160 (5), 23-26. doi: http://doi.org/10.31550/1727-2378-2019-160-5-23-26

11. Ueda, S., Uchiyama, S., Azzi, T., Gysin, C., Berger, C., Bernasconi, M. et. al. (2013). Oropharyngeal Group A Streptococcal Colonization Disrupts Latent Epstein-Barr Virus Infection. The Journal of Infectious Diseases, 209 (2), 255-264. doi: http://doi.org/10.1093/infdis/jit428

Received date 05.08.2021

Accepted date 14.09.2021

Published date 30.09.2021

Viktoriia Olkhovska, Postgraduate Student, Department of Pediatrics, Kharkiv Medical Academy of Postgraduate Education, Amosova str., 58, Kharkiv, Ukraine, 61176

Zalina Yeloyeva, Doctor of Medical Sciences, Professor, Department of Pediatrics, Kharkiv Medical Academy of Postgraduate Education, Amosova str., 58, Kharkiv, Ukraine, 61176

Yevhen Olkhovskyi, Assistant, Department of Pediatrics No. 1 and Neonatology, Kharkiv National Medical University, Nauky ave., 4, Kharkiv, Ukraine, 61022

*Corresponding author: Viktoriia Olkhovska, e-mail: vikaolkhov91@gmail.com 